This item was submitted to Loughborough's Research Repository by the author.

Items in Figshare are protected by copyright, with all rights reserved, unless otherwise indicated.

\title{
Physical education's journey on the road to health
}

\section{PLEASE CITE THE PUBLISHED VERSION}

https://doi.org/10.1080/13573322.2020.1740979

\section{PUBLISHER}

Informa UK Limited, trading as Taylor \& Francis Group

\section{VERSION}

AM (Accepted Manuscript)

\section{PUBLISHER STATEMENT}

This is an Accepted Manuscript of an article published by Taylor \& Francis in Sport, Education and Society on 17 March 2020, available online: http://www.tandfonline.com/10.1080/13573322.2020.1740979.

\section{LICENCE}

CC BY-NC-ND 4.0

\section{REPOSITORY RECORD}

Cale, Lorraine. 2020. "Physical Education's Journey on the Road to Health". Loughborough University. https://hdl.handle.net/2134/11993688.v1. 
Physical Education's Journey on the Road to Health

\section{Author Lorraine Cale}

Lorraine Cale L.A.Cale@,lboro.ac.uk

Professor in Physical Education and Sport Pedagogy

School of Sport, Exercise and Health Sciences, Loughborough University, UK

Adjunct Professor in Sport Pedagogy at the University of Limerick, Ireland 


\begin{abstract}
Each year, the British Educational Research Association (BERA) Physical Education and Sport Pedagogy Special Interest Group organizes an Invisible College which precedes the annual BERA conference. The day opens with a Scholar Lecture which is delivered by an academic who has made a significant contribution to the field. This paper represents the 2019 Scholar Lecture, which charts the journey of health within physical education over recent decades through to the present day. Whilst the notion of maintaining health through physical education is long standing and contributing to healthy active lifestyles is generally accepted to be a key goal of the subject, it is argued that the road to securing and retaining the position of health within the curriculum has at times been tricky to navigate. There have certainly been many successes en route, but equally some challenges and seemingly even a few obstacles and diversions.

Specifically, this paper outlines the journey of health from the $1980 \mathrm{~s}$, during which time there was revived interest in health and a significant growth in health-related courses within physical education curricula within and beyond the United Kingdom. This coincided with the introduction of the National Curriculum in England and Wales, as well as with my own doctoral studies and initial physical education practice. Consequently, I highlight key influences and influencers in the area and on my thinking during this period, as well as some of the key developments, outcomes and messages emanating from this early work. Equally, I explore some of the issues and challenges health and health-related learning within physical education have and continue to face. The paper then turns to focus on recent progress and positive developments in the area and concludes with some proposed future directions for research and practice and reflections on the next leg of the journey for health within physical education.
\end{abstract}

\title{
Key Words
}

Physical education; health; physical activity; schools 


\section{Introduction}

It was a real privilege to deliver the Scholar Lecture at the 2019 Physical Education and Sport Pedagogy (PESP) Special Interest Group Invisible College and I'd like to thank PESP committee members for the invitation to do so. Each year, the British Educational Research Association (BERA) PESP Special Interest Group organizes this event to precede the annual BERA conference with the day opening with such a Lecture. In planning this, I reflected back on my career as both a physical education researcher and practitioner, which began in the United Kingdom (UK) in the late 1980s, and on my particular interest in health within our subject. This included reflecting on the key influences and influencers on my work at this time. Whilst there have certainly been many, one individual, Len Almond, demands most acknowledgement and this explains the content of much of the Lecture. I return to this point at the end.

In my preparations, I was also mindful that Mikael Quennerstedt gave a really excellent and thought provoking Scholar Lecture on the same broad topic area in 2018 (see Quennerstedt, 2019). In his presentation, Quennerstedt explored the concepts of health and learning and shared his views and vision as to how health and health education should be seen and approached in physical education; and evidently we are 'on the same page' in many ways in this regard. Thus, whilst not revisiting or repeating Quennerstedt's previous words, this Lecture should reinforce and complement them.

In this Scholar Lecture, I aim to chart the journey of health within physical education over the past few decades through to the present day. Specifically, the journey starts in the 1980s. The key influences and influencers in the area and on my thinking during this period, as well as some of the 
key developments, outcomes and messages emanating from this early work are highlighted. Equally, some of the issues and challenges health and health-related learning within physical education have and continue to face are explored. Having considered these, the Lecture turns to focus on recent progress and positive developments in the area before concluding with possible future directions for research and practice and reflecting on the next leg of the journey for health within physical education.

At the outset, it should be acknowledged that various terms have been used to refer to this area over the years. Examples include health-based physical education, health-related physical education, or health-related exercise or health-related fitness. For the purpose of this Lecture, the term healthbased physical education (HBPE) is adopted with all other variants seen to be synonymous, with this broadly referring to:

'the teaching of knowledge, understanding, physical competence and behavioural (and other) skills, and the creation of positive attitudes and confidence associated with current and lifelong participation in physical activity' (Harris, 2000, p. 2).

\section{Setting Out (Early UK Developments)}

Whilst the notion of maintaining health through physical education is long standing and contributing to healthy active lifestyles is now generally accepted to be a key goal of the subject, in the decades leading up to the 1980s other objectives and notably the acquisition of physical skills had been afforded priority in the curriculum for many years (Cale \& Harris, 2013). In the 1980s though, health once again became prominent within physical education. This period also coincided 
with the start of my career and hence coincidentally was the first leg of my health in physical education journey.

In the UK, the renewed interest at this time was very much instigated by Len Almond who was instrumental in driving developments and establishing the HBPE 'movement'. Evidence of this was seen in the significant growth in the number of health-related courses which were introduced in schools' physical education curricula across the country. Indeed, in the late 1980s there was reportedly a virtual tenfold rise in schools incorporating a health-based approach within the subject (Almond, 1989). Furthermore, in the years that followed a growing number of UK-based researchers and physical educators began to contribute research papers, reviews and debates to the area (e.g. Almond, 1991; Armstrong, 1990; Cale, 1996; Fox, 1992; Green, 1994; Harris \& Elbourn, 1992a, 1992b; Harris, 1994, 1995; Sleap, 1990), further reinforcing and establishing the popularity and importance of HBPE.

Central to and providing momentum for the above in the UK was arguably the Health Education Authority (HEA) Health and Physical Education Project. Based at Loughborough University and led by Len Almond, the project ran from 1985-1993 and was the first of its kind to actively promote health-related work in physical education in schools. I was fortunate to be given the opportunity to join the project team in 1990, supporting its work alongside undertaking my $\mathrm{PhD}$. The project delivered professional development courses and seminars for teachers and advisers across the UK and produced numerous school-based resources, initiatives and regular newsletters to support its work (HEA, 1993). Whilst the limitations of professional development courses and curriculum resources and initiatives of this nature are recognized (Armour \& Harris, 2013), these developments were highly significant in that they were based on new philosophical principles and approaches and 
provided much needed teacher support in the area at the time.

Also of influence and reinforcing the acceptance and importance of HBPE around this time, was the National Curriculum for Physical Education (NCPE) in England and Wales which was first introduced in 1992. A key question advocates of the area were asking during the National Curriculum proposal stage was whether HBPE would be included within the NCPE, and if so, in what form and context. Indeed, its inclusion was considered essential to the future development and progress of HBPE in schools (Cale, 1996). Len Almond fought hard to ensure HBPE was not overlooked. In an Open Statement to the NCPE Working Group members (the group tasked with advising government on the statutory order), he presented a convincing case for HBPE to be included and identified the features and associated knowledge base he viewed to be critical for pupils from 5-16 years (Almond, 1991). Whilst Almond $(1989,1991)$ acknowledged sport, dance and adventure activities to be major elements of the physical education curriculum, he proposed that the key to pursuing any type of purposeful physical activity in depth was firstly a commitment to HBPE. Almond (1991, p. 29) claimed the area to be the 'core' of all physical education because 'it provides the foundation from which excellence or a commitment to purposeful physical activity as an absorbing activity can enhance the quality of one's life.'

Not all of Almond's recommendations found their way into the statutory order, but certainly elements and the crux of what he proposed did. Health was included as a compulsory component of the NCPE across all Key Stages and as a cross-curricular theme of health education (Department for Education \& the Welsh Office, 1995; National Curriculum Council, 1990). This was a key milestone for HBPE, giving it for the first time a formally recognised, clearly defined knowledge base and place in the curriculum (Cale \& Harris, 2005). Thus, from this time, health became firmly 
established within the NCPE and has assumed increasing prominence within successive iterations. To illustrate, in the current NCPE for England, ensuring that all pupils 'lead healthy, active lives' and 'are physically active for sustained periods of time' represent two of the main aims of the subject (Department for Education, 2013, p. 1). Furthermore, although the early journeys of health within physical education have varied from country to country in terms of the route taken and main drivers, it should be noted that parallel interest and developments were seen elsewhere within and beyond the UK. Consequently, health has become a key component within the aims or purpose of the curricula in many countries including, for example, in Scotland, Wales, Ireland, Australia and New Zealand to name just a few (see Lawson, 2018).

\section{Milestones}

As alluded to earlier, alongside and integral to these early HBPE developments was the establishment of a clear philosophy for the area. For HBPE to be effective and for it to foster in young people the required competence, behavioural (and other) skills, attitudes and confidence associated with current and lifelong participation in physical activity (Harris, 2000), it was recognised that delivery needed not only acquisition of a new knowledge base for many teachers, but a different philosophical approach and emphasis to delivery as well (Cale, 1996). In a short but seminal article at the time, entitled 'Learning to Care', Harris and Almond (1991, p.6) highlighted how central to HBPE was 'every child' and the notion that 'everyone can be good at exercise' and 'everyone has the right to positive experiences of exercise.' Thus, the 'child' was placed very much at the core and there was a deliberate shift away from the preoccupation with traditional activities such as games or athletics and physical skills and techniques which hitherto had characterized the delivery of the subject. Other and related philosophical principles or messages from this earlier work included the notion that physical activity was for all, physical activity was for life, and that 
everyone can benefit from physical activity, with excellence being seen as maintaining an active way of life (see Cale \& Harris, 2009a; Harris \& Cale, 2018).

To achieve the above, there was a call for the physical education profession to humanise and personalise physical activity experiences to ensure they were satisfying, enjoyable, meaningful and relevant to the future lives of young people (Harris \& Almond, 1991). It was suggested the teacher's task was to help all young people to learn to love being active, and through this and a commitment to active living, flourish as individuals. Hence, there was an explicit commitment to inclusion, equity, democracy, empowerment and a refocusing towards physical activity for life. In support, and with a view to creating positive, rewarding, meaningful, contextually relevant and inclusive physical activity experiences for young people, a number of enabling principles (to adopt) and inhibiting practices (to avoid) were identified. The enabling principles were seen to be ethical and grounded in a commitment to the above values and included, for example, setting attainable tasks and challenges, rewarding effort, valuing pupils' contributions, encouraging pupil independence, asking pupils if they wish to share work and ensuring fair competition against others. Meanwhile, example inhibiting practices included exposing pupil incompetence, setting monotonous or repetitive drills, rewarding performance only, treating pupils as 'empty vessels', keeping pupils dependent on the teacher, demanding pupils to display their work, and allowing unfair competition against others (Harris \& Almond, 1991).

These days the enabling principles just seem to reflect common sense, good pedagogical practice and certainly philosophical strides in physical education (and education) have been made in recent years. Indeed, some of these principles are now enshrined in law. During this era however, and hampering the above, was the reported strong performance-oriented philosophy which dominated 
physical education (Almond, 1989). Almond (1983, p. 9) contended that the physical education curriculum was 'really competitive sport for many teachers', meaning this new and more childcentred philosophy and 'caring pedagogy' was likely to have been quite alien to many teachers. Interestingly, though perhaps to a lesser extent, evidence suggests that this still remains the case. This point is returned to later.

In terms of pedagogy, central to HBPE was practical and experiential learning and the acquisition of a practical knowledge base through the area, with this approach reflecting the physical context of the subject and making a positive contribution to young people's overall physical activity levels (Harris, 2000; Harris \& Cale, 2018). Proponents thus advocated that HBPE should involve the development of health knowledge and skills through active participation in a range of activities and via a combination of understanding, experiencing, decision making and evaluating (Cale \& Harris, 2013; Cale, 2017). Almond (1983, p. 8) explained ' ... young people must not equate these new courses with the usual classroom type lessons...', and asserted that the area needed to be taught 'in a practical and experiential way and NOT as some kind of theoretical lesson' (Almond, 1990a, p.20). Once again though and as highlighted later, this reflected the practice of some.

Alongside advocating a new philosophy and pedagogy and in on-going efforts to advance HBPE as a valued component of the curriculum, Almond $(1983,1989)$ and subsequently myself and others, challenged other aspects of traditional physical education practice which were felt to be contrary to achieving health-related learning goals. This included questioning both the content and quality of the curriculum. In this respect, Almond $(1983, \mathrm{p} 6)$ called for 'radical changes' in developing HBPE spanning content, curriculum design and organisation, and extra-curricular provision. Almond (1990a) valued all forms of 'purposeful' physical activity in terms of its potential to 
contribute to active lifestyles which might include sport (lifestyle sports, play sport and competitive sport), dance, outdoor adventure, and individual activities, but equally contended that some aspects of health-related learning could not be taught via a traditional activity focused curriculum. He was thus keen for there to be a move away from a purely activity based curriculum (e.g. comprising athletics, gymnastics swimming, games, dance) and for the development of new health-focussed modules or units which could incorporate a broader range of activities (e.g. fitness-related activities, aerobics and circuit training) as well as other health-related aspects of learning (e.g. lifestyle management, goal setting, planning an exercise programme) (Almond, 1990a, 1990b). This broader vision therefore extended the traditional, competitive team-sport orientated physical education curricula in place at the time to cover education about lifetime physical activity, physical activities (Harris, 2010) and lifestyle skills. Beyond HBPE and of further significance was also recognition of the value of cross-curricular links and working with other subjects, plus the role of wider aspects of the school and whole school approaches in promoting health and health-related learning (Almond, 1990, 1990b).

\section{Diversions and Obstacles}

Despite the vision and aspirations Len Almond, myself and others had for HBPE in the early years, in practice there were, and continue to be, challenges in realising these and curricular realities did not meet expectations. There was seemingly some misunderstanding and confusion over HBPE in terms of its position, interpretation and expression in the curriculum (Fox, 1992; Harris, 1994) with delivery of the area found to be characterised by lack of coherence, limited systematic expression and much variation in practice (Harris, 1995). Indeed, only recently, Green et al. (2018, p. 158) have claimed how HBPE has been found 'wanting on several fronts' and to represent 'small degrees of change alongside considerable continuity' (p. 159). Collectively the above have led to some 
diversions, obstacles and questionable practices over the years, just a few of which are outlined below.

Firstly, despite firm advocacy that practical and experiential learning should be central to HBPE, some interpreted it to be all about theory and resorted to classroom-based delivery of the area. This approach is clearly at odds with Almond's early recommendations and with the physical nature of the subject and is limiting in terms of the types of experiences and learning it affords young people (Cale, 2017; Cale \& Harris, 2006). Others meanwhile, interpreted practical and experiential learning to be little more than involving children in vigorous activity (Oxley, 1994), or to involve 'drill', 'running children hard' (Cale \& Harris, 2009a; Harris \& Elbourn, 1992b), to be just about aerobics, circuit training and cross country, or primarily concerned with warming up and cooling down or fitness testing (Harris \& Elbourn, 1992b). While these types of activities may seem attractive 'quick fix' solutions to address concerns over children's health and physical activity and increase fitness in the short-term, they are considered problematic on many grounds. For example, they are narrow in focus, directed, repetitive and may lead to dull, boring, unappealing, undesirable and inappropriate practices which could be counterproductive to the promotion of active lifestyles (Cale $\&$ Harris, 2009a; Cale et al., 2020). Furthermore, concerns were raised that the delivery of these types of activities in the name of HBPE often involved minimal or no learning (Harris, 1993). Certainly, they were a far cry from the more personalised, student-centred approaches and to helping young people to learn to love being active which many of us were working hard to promote.

One particular diversion and questionable practice was fitness testing, which remains a standard feature of physical education today (Alfrey \& Gard, 2019; Cale et al., 2014). According to Wrench and Garrett (2008, p. 341), fitness testing has seemingly become 'normalized' and 'taken for 
granted' pedagogical practice within the subject. Indeed, a study by myself and colleagues involving over 100 secondary schools in the UK found most schools (89.0\%) to monitor pupils' physical fitness within the physical education curriculum and many (47\%) to assess it on a compulsory basis two or three times a year (Cale et al., 2014). Meanwhile, a similar study in Australia found fitness testing to be the most popular context for teaching about health (Alfrey \& Gard, 2014). Yet, fitness testing has and continues to be widely debated by researchers (e.g. Alfrey \& Gard, 2014, 2019; Cale, 2017; Cale \& Harris, 2009b; Keating, 2003; Wrench \& Garrett, 2008) with various issues raised concerning the ethics and value or purpose of testing young people in particular (Cale \& Harris, 2009b). There is not scope to discuss these in detail here, but in short, there is still little evidence to support the notion that fitness tests contribute to the promotion of healthy active lifestyles, as advocates of testing purport them to do (Cale, 2017). To the contrary, it has been reported that testing can be counterproductive to this goal in that it can be unpleasant, uncomfortable, embarrassing and even shaming for many young people, and scores can be inaccurate, misleading, unfair, meaningless and thereby de-motivating and detrimental to the confidence of young people (Alfrey \& Gard, 2019; Cale \& Harris, 2009b; Naughton et al., 2006). Further limitations include the individualistic nature and performative culture reflected in and reinforced through fitness testing and some testing practices (Alfrey \& Gard, 2014; Cale \& Harris, 2009b; Cale et al., 2014; Wrench \& Garrett, 2008), the concerns over which for young people, for example, with respect to their identity, education and health have been reported elsewhere (e.g. Alfrey \& Gard 2014; Cale \& Harris, 2009a; Evans, 2007; Evans et al., 2008; Evans \& Rich, 2011; Sykes \& McPhail, 2008; Wrench \& Garrett, 2008).

The continued uncritical focus on fitness testing is thus questionable on many levels. That said, there are still proponents of fitness testing (e.g. Silverman et al., 2008; Lloyd et al., 2010), potential 
benefits, as well as pockets of reported good practice, and we should therefore avoid generalising or demonising all fitness testing practice. In Sweden, for instance, Larsson and Quennerstedt (2016) note that testing takes on a different form and avoids many of the pitfalls just noted. Plus, the reality is that testing remains a popular component of physical education for many reasons, not least because it is easy to administer, convenient, familiar and historically rooted (Alfrey \& Gard, 2014, 2019; Cale, 2017). Fitness testing guidelines and recommendations for young people have also been published over the years, including some by myself and colleagues (Cale et al., 2014).

Notably though, our recommendations focus on monitoring within the curriculum more broadly and holistically, covering health, physical activity and fitness monitoring, and include key principles, messages and values teachers should strive to adopt in their practice as well as guidance on content, organization and delivery (Cale et al., 2014). Importantly, they advocate a critical and learnercentred approach and for teachers to encourage their students to likewise be critically reflective and appreciate the caveats of such practice. In light of this, it is accepted that, if appropriately employed, subjected to informed critique, and incorporated as just one component of a broad and holistic educational programme, then fitness testing can be a valuable component of the physical education curriculum and play a role in promoting healthy active lifestyles (Cale \& Harris, 2009b; Cale et al., 2014; Lloyd et al., 2010; Silverman et al., 2008). But, given the limitations, continued prevalence and such heavy emphasis on fitness testing, it could be claimed it is an unnecessary diversion, a misdirected effort, and that valuable and in many cases diminishing physical education time could be better spent. Is it therefore time to do a u turn and steer away from testing all together?

Returning to the issue of limited learning within and through HBPE, a further obstacle was that even when learning was evident, there was often a lack of progression in this. Indeed, such 
concerns are still pertinent today and have been reported in Ofsted inspection reports (Office for Standards in Education, 2005) and observed in practice (Harris \& Leggett, 2015). Minimal or lack of progression in learning may stem from the fact that, despite health featuring as a component within successive versions of the NCPE, references to health-related learning and to health-related activities in the actual programmes of study have and still remain 'somewhat limited and more implicit' (Cale \& Harris, 2018, p.281). How specifically the NCPE aims are to be achieved and the programmes of study addressed such that pupils have the requisite knowledge and skills with respect to healthy active lifestyles is thus still open to debate (Cale et al., 2020). Consequently, teachers are left to interpret the requirements and what HBPE learning should look like to achieve the requirements for themselves. In absence of such steer, and given some of the additional challenges that are identified later, it is perhaps not surprising that many of the narrow and questionable practices highlighted earlier took hold and remain, as teachers continue to grapple with the area resorting to what they know and feel comfortable delivering. Understandably, this largely stemmed from their previous studies and training which typically and increasingly has involved emphasis on the hard sciences, the bio-physical body, and quantitative evaluation arising from what has been referred to as the scientisation of physical education (Alfrey \& Gard, 2019; Kirk, 2010).

To address this obstacle as well to support the interpretation and delivery of the health requirements within the NCPE and health-related learning generally, a working group was established in the late 1990s (Harris, 2000; Cale \& Harris, 2018). The group, led by Jo Harris, included Len Almond, myself, other academics, plus representatives from schools and key national sport, health and physical education organisations, a key output of which was good practice guidelines for teachers and health-related outcomes for children aged 5 to 16 (Harris, 2000). The outcomes, which have recently been updated (see Harris \& Cale, 2018), included cognitive, affective, and behavioural 
components presented in four categories or areas of learning: safety issues, exercise effects, health benefits, and activity promotion. To illustrate the expected progression in learning across these four areas the outcomes were also grouped by key stage (KS) or age range (i.e. 5-7 years (KS1); 7-11 years (KS2); 11-14 years (KS3) and 14-16 years (KS4)). All areas were deemed important and relevant to current and lifelong participation in physical activity and aimed to equip young people with a progressively sophisticated level of knowledge and understanding concerning: i) participating safely and effectively in physical activity (safety issues); ii) the body's response to physical activity participation (exercise effects); iii) the benefits of participating in physical activity (health benefits); and iv) what physical activity to participate in, where and how (activity promotion) (Cale \& Harris, 2018).

However, despite this work and likely linked to the scientisation of physical education, research has revealed that the more 'physical' and 'instrumental' outcomes, for example, those relating to safety issues (e.g. safe practice and warming up and cooling down) and to exercise effects (i.e. the short term effects of exercise on the body) are afforded more attention in HBPE delivery than those associated with health benefits and activity promotion (Harris, 2010; Cale \& Harris, 2018). Others (e.g. Alfrey \& Gard, 2014) have similarly acknowledged the profession to be focussed on the dualistic and instrumental understandings of health and the body and how in turn this leads to many teachers applying these same narrow instrumental outcomes in their delivery. This is noteworthy in that, whilst all categories and outcomes clearly have a place and represent valuable learning, it is the others (i.e. health benefits, activity promotion) which are considered to be most closely linked to successful engagement in lifetime physical activity (Cale \& Harris, 2018). The need for a broader and more balanced approach which pays good attention to health and activity promoting outcomes 
and which focuses on development across all domains of learning, the cognitive, psychomotor, behavioural and affective, is therefore recommended (Harris, 2000; Harris \& Cale, 2018).

Related to the interpretation of HBPE and the desired outcomes, it is important to appreciate the complexity of physical activity and physical activity behaviour change and that, knowing 'that', does not simply translate into 'doing' (Tinning, 2010, p.181). Not only would such an association be overly simplistic and 'naïve', but it would seem to be controlling rather than empowering and contrary to the philosophy of the HBPE movement. If we are committed to personalising learning and putting young people's individual needs and interests at the core, trying to mould all young people into our definition of good (with good referring to 'active') citizens would seem to be morally and ethically indefensible. This of course raises questions about the actual role of physical education in health. As noted earlier, that physical education has a role to play is largely widely accepted but the nature and extent of this has, and continues to be, debated (Armour \& Harris, 2013; O’Sullivan, 2004; Quennerstedt, 2008). Evidently, physical education can only achieve so much and it is important to be realistic in what it can, and to appreciate the limitations and boundaries. For example, physical education cannot meet all of young people's physical activity and health needs (Fox et al., 2004; McKenzie \& Lounsbery, 2009), ensure they lead physically active lifestyles beyond school and hence meet physical activity recommendations, nor 'solve obesity, physical inactivity, drug misuse... youth suicide etc' (Macdonald et al., 2018, p. 202). That said, it is argued that physical education needs to do what it can in the time available to stimulate interest, enjoyment, knowledge, competence and expertise in physical activity and sport for health and well-being (Fox et al., 2004) amongst all young people. This includes equipping them with the knowledge and skills to access and appraise resources, apply health-related knowledge, and evaluate personal progress towards active living (Macdonald et al., 2018). In addition, it involves giving young 
people the knowledge and skills to be able to critique the health information and messages they are increasingly bombarded with from various sources (Cale, 2019) so that they feel empowered and can make informed, independent decisions about their own health and health behaviours. In summary, young people need to be supported to become critical consumers of health-related information (Macdonald et al., 2018). The commitment to the philosophy and principles outlined earlier, the provision of high quality teaching (Cale \& Harris, 2013), and to a more socially-critical perspective to teaching and learning about health are central to enabling and facilitating this. The importance of the latter perspective is increasingly being recognised (Burrows et al., 2009; Haerens et al., 2011; Quennerstedt, 2008) and indeed, it is an explicit and firmly embedded aspect of the Health and Physical Education curriculum in Australia (ACARA, 2012) from which we could learn much in the UK. More is said about this later.

Given the above challenges it is perhaps not surprising that some authors are sceptical of physical education's role in health and have raised concerns over the uncritical, simplistic and narrow way in which schools and teachers arguably engage in health issues and ultimately translate and express them in their curricula and pedagogies (see Burrows \& Wright, 2004; Evans, 2007; Evans et al., 2008; Evans \& Rich, 2011; Wellard, 2012). However, rather than be overly critical or cynical about the unintended outcomes and practice limitations just outlined, if we are to move forwards it is important to try to understand and address the root causes of these, plus learn from the existing good practice, recommendations and developments which have taken place within and beyond the UK. A number of factors have led to the above and arguably hindered the progress of HBPE and teachers' ability to embed good practice in schools over the years. From the outset Almond (1983, 1989) cited lack of time, the dominance or preoccupation with competitive sport in the curriculum, lack of teacher resources and a lack of knowledge of 'how to start' as barriers posing challenges and 
constraints to progress. Some of these issues persist today, a recent overview of which is offered elsewhere (see Cale et al., 2020). For example, Cale and colleagues highlight the relatively low or marginal status afforded to health within physical education (Alfrey et al., 2012; Cale et al., 2016) as an obstacle, with increasing pressures for academic accountability and results-driven curricula reportedly prioritising other subjects and restricting the attention afforded to areas such as health (Larsen et al., 2013; Marks, 2008) and physical activity particularly (Cardon et al., 2012). In addition, physical education, in most secondary schools at least, is taught by specialist physical education teachers who are reputed to be traditional and resistant to change (Alfrey \& Gard, 2014; Kirk, 2010). This reinforces the preoccupation with traditional activities, competitive sport, and the dominance of sport techniques and skills and teacher directed approaches which it is suggested stem from their sport and performance-oriented backgrounds and philosophies (Alfrey et al., 2012; Green 2009; Kirk, 2010; Thorburn \& Gray, 2010; Trost, 2006). Most recruits to the physical education profession are reported to be physically active, fit, individuals who typically love and participate extensively in sport (Kirk et al., 2018, Lawson, 2018). This purportedly influences their delivery of health (Alfrey et al., 2012; Cale \& Harris, 2013) and also explains the privileging of the 'fitness' and 'performance' oriented approach to HBPE discussed earlier and the persistence of fitness and fitness-related activities as vehicles for delivering the area (Alfrey et al., 2012; Harris \& Leggett, 2015; Puhse et al., 2011). These issues are then further compounded by the subsequent lack of relevant initial or continuing professional development in the area. To illustrate, Alfrey et al. (2012) found approximately half of UK physical education teachers to have had no prior experience of health within physical education whatsoever before teaching it, and $70 \%$ to have accessed no related professional development in the previous three years. This unsurprisingly leaves physical education teachers lacking the health knowledge, skills and pedagogies to be able to effectively promote physical activity and health (Alfrey et al., 2012; Armour \& Harris, 2013; Cale et al., 2016). 


\section{Recent Milestones}

Despite the various issues and challenges, there have been some encouraging and noteworthy developments of late both within and beyond the UK, and from which we can learn and build upon. In terms of curriculum, arguably more progress has been made in other countries. For example, the new Australian Health and Physical Education curriculum is said to provide a 'road map' for what might be considered a redesigned curriculum (Macdonald et al., 2018, p. 206). Whilst historically, Health and Physical Education in Australia adopted a risk-based model (Macdonald et al., 2018), their new 'futures-oriented' curriculum is underpinned by the following five interrelated propositions: a focus on educative outcomes; adopting a strengths-based approach; the development of health literacy skills; valuing learning in, about and through movement; and a critical inquiry based approach (Australian Curriculum, Assessment and Reporting Authority, 2012). This includes developing young people's ability 'to selectively access and critically analyse information and take action to promote their own and others' good health' (Macdonald et al., 2018, p.24). Likewise, over time New Zealand has reportedly seen a clear shift in their curriculum, away from the traditional fitness, team sport and biomedical focus (Burrows, 1999, cited in Dyson et al., 2018) towards wellbeing (of students, others, and of society). Four underlying concepts guide learning within their new Health and Physical Education curriculum (Ministry of Education, 2007) including attitudes and values, Hauora (a Maori philosophy of well-being), health promotion and a socio-ecological perspective (Dyson et al., 2018).

With regards pedagogical developments, just a few examples include the Health-Based Physical Education (HBPE) Model (Bowler, 2019; Haerens et al., 2011), the Promoting Active Lifestyles (PAL) Project (Cale et al., 2020; Harris et al., 2016; Harris \& Cale, 2018), Health Optimizing 
Physical Education (Metzler et al., 2013), and The Project-Based Learning Model (Hastie et al., 2017). Although distinct in their own right and whilst there is not scope to discuss these developments in detail here, they all appear to uphold Almond's broad philosophy, values and aspirations with respect to physical activity and promoting active lifestyles. In addition, and to highlight just two over the others, the HBPE Model includes the different domains of learning, and notably the affective domain, having as its central theme 'pupils valuing a physically active life' (Haerens et al., 2011, p. 321). Further, it draws on the social ecological model alongside other theories, namely self-determination theory and theories of behaviour change, in supporting learners to become habitual, motivated, informed and critical 'movers' (Bowler et al., 2015; Bowler, 2019). Thus, the importance of valuing a physically active life, developing knowledge, and of looking beyond the individual to the wider community are all reinforced. Similarly, the PAL Project is underpinned by the social ecological model, alongside social cognitive theory, and thereby spans the different domains. The Project represents a principles-based approach to promoting active lifestyles designed primarily to inform both whole school and physical education policies and practices in promoting active lifestyles. Some principles focus on the development of knowledge and understanding (e.g. teach pupils about the broad range of benefits of a healthy active lifestyle), while others are concerned with influencing pedagogy (e.g. manage assessment of pupils' learning and progress in active ways), or the wider school environment to make it more conducive to physical activity (e.g. promote active travel to school) (Harris et al., 2016; Harris \& Cale, 2018). Both the HBPE model and the PAL Project have resulted in some positive outcomes for teachers and teachers' practice, as well as for pupils (Bowler et al., 2015; Bowler 2019; Harris et al., 2016).

\section{Next Leg of the Journey}


Evidently what is required on the next leg of the journey is consistent and widespread good pedagogical practice with respect to HBPE. Key principles of such practice include studentcentred, inclusive, contextually relevant, and active and engaging experiences, and the desired outcomes from which should be confident, empowered, independent and resilient individuals who value, enjoy, are motivated and have positive attitudes towards and a desire to lead healthy active lifestyles. Yet, despite the positive developments just outlined, knowledge about effective health pedagogies is still lacking and has been identified as a significant gap in the field (Armour \& Harris, 2013; Hastie et al., 2017). The current work on different pedagogical models and approaches to delivering health should therefore continue and be further developed to enhance the evidence base and inform our practice. Related to this and in recognition of the importance of the affective domain, some advocate the need for pedagogies of affect (Kirk et al., 2018; Kirk, 2019). Reflecting on the situation and curriculum in Scotland, Kirk et al. (2018) see the development of pedagogies of affect as a redesign challenge and opportunity whereby affective learning is seen as a central educational outcome rather than merely a bi-product of physical education. This focus certainly resonates with Almond's earlier vision to help all young people to learn to love being active through the provision of positive, relevant and appropriate activity experiences. Indeed, the rationale for focussing explicitly on pedagogies of affect is also convincing given the growing prevalence of poor mental health and well-being among young people (Biddle et al., 2019; World Health Organisation, 2018). This has arguably emerged as a much more widespread and pressing health issue than was the case during the HBPE movement of the 1980s, and one which now warrants serious attention. Thus, research into pedagogies of affect and supporting teachers to explicitly build young people's affective attributes including confidence, motivation, determination, selfesteem and resilience through physical education is important (Thorburn, 2018) and should not be left to chance. 
Also key to effective work in this area is understanding young people and their health behaviours and giving them voice and influence. For example, understanding and being sensitive to their development, characteristics, backgrounds, perspectives, interests and lifestyles (Cale \& Harris, 2009a), and asking what physical activity journey have they been on?, or haven't they?, and what journey do or might they aspire to, or not, and for what reason(s)? Only then can we begin to effectively support them. In short, we need to listen to, engage with, and empower young people to influence their health-related learning and opportunities (Cale \& Harris, 2009a; Leahy et al., 2016; Oliver \& Kirk, 2016) and thereby promote their agency. Young people and young people's experiences being at the heart of our efforts and the process is again central to the principles of good, effective pedagogy. Student-driven, participatory pedagogies (Enright \& Gard, 2019) and activist approaches (Oliver \& Kirk, 2016) which involve a shift in the power dynamic between teacher and pupils, as well as strengths-based approaches (Macdonald et al., 2018) which recognise young people's strengths, interests and encourage their agency are all appealing in this regard and have real potential and applicability to HBPE.

Finally, attention needs to be paid to the use and influence of digital technologies to support pedagogy in HBPE, which it is contested represents another emergent and more pressing issue since the inception of the HBPE movement. Numerous health-related apps, wearables, and sites are now available (Goodyear et al., 2017; Rich \& Miah, 2017) and being used to support health-related teaching and learning within physical education (Casey et al., 2017; Gard, 2014). As with any tool or resource, if used well they may facilitate health-related learning, foster positive attitudes and motivate young people to be physically active. Yet, concerns have been expressed over the potentially negative impact they might have on teachers' practice, pupils' learning and/or their 
wellbeing (Cale et al., 2020). Potential issues with such technologies include their tendency to quantify and limit health-related learning, for example, by measuring, ranking or tracking pupils (Goodyear et al., 2017; Lupton, 2016), further reinforce a narrow, fitness focus within physical education (Cale et al., 2020), or to promote unhealthy surveillance practices (Rich and Miah, 2017; Williamson, 2015). As noted earlier, young people need to be supported to become critical consumers of health and this should extend to the use of digital health technologies and to the health information, messages and behaviours these technologies convey and promote (Cale, 2019).

\section{Concluding Thoughts}

This Scholar Lecture has charted the journey of health within physical education and some of the work of Len Almond, myself and others in this area from the 1980s onwards. It has identified some of the key developments, outcomes and messages of this work as well as a number of on-going issues and challenges associated with health and health-related learning within the subject. Whilst there have been many successes en route, the road to these has not always been smooth and some diversions and obstacles have been faced along the way. We thus need to continue to work hard to navigate these and ensure they do not divert or block our efforts. Only in this way will we be able to effectively support young people to become physically active both now and in the future. The optimistic navigator in me believes these are not unsurmountable and indeed, there are some new and very encouraging developments and opportunities for HBPE which, if embraced, have the potential to positively impact the health and lives of our young people. To realise these, collective effort, responsibility, and commitment to 'every child' and to good pedagogical principles and practice are required to ensure all young people receive the quality health-related learning experience they deserve. In essence, this amounts to a return or $u$ turn to the original intentions of 
the HBPE movement in our work, whilst taking into account and reflecting the new developments, opportunities, health issues and demands facing the youth of today.

\section{Final Acknowledgments}

The Scholar Lecture ended returning to acknowledge the work and influence of Len Almond in particular, with the following words. Len sadly passed away in May 2017, but had a huge influence on myself, my work, and on HBPE over many years. As a former lecturer, my PhD supervisor, and subsequently line manager and colleague, he mentored, challenged and inspired me greatly and his influence still drives me to want to make advancements to the area today. Thus, I would like this lecture to serve as a personal tribute to Len and contribute in part to his legacy in the field. In addition, I would like to acknowledge other colleagues who I've worked very closely with over the years, as researchers and/or practitioners, including Jo Harris, Jill Elbourn, John Evans and others, plus former and current $\mathrm{PhD}$ students who, through their ideas, reflections, enthusiasm, dedication, and determination have equally challenged and inspired me, and I know will continue to do so.

\section{References}

Armstrong, N. (1990). New directions in physical education. Volume 1. Leeds: Human Kinetics.

Alfrey, L., \& Gard, M. (2014). A crack where the light gets in: a study of health and physical education teachers' perspectives on fitness testing as a context for learning about health. AsiaPacific Journal of Health, Sport and Physical Education, 5(1), 3-18.

Alfrey, L., \& Gard, M. (2019). Figuring out the prevalence of fitness testing in physical education: A figurational analysis. European Physical Education Review, 25(1), 187-202.

Alfrey, L., Cale, L., \& Webb, L.A. (2012). Physical education teachers' continuing professional development in health-related exercise. Physical Education and Sport Pedagogy, 17(5), 477-491.

Almond, L. (1983). A rationale for health-related fitness in schools. The Bulletin of Physical Education, 19(2), 5-10.

Almond, L. (1990a). A Health-related exercise focus in physical education. The Bulletin of Physical Education, 26(1): 18-21. 
Almond, L. (1990b). Four questions about a National Physical Education Curriculum. The Bulletin of Physical Education, 26(1), 5-8.

Almond, L. (1989). New wine in a new bottle-implications of a National Physical Education Curriculum. The British Journal of Physical Education, 20(3),123-125.

Almond, L. (1991). An open statement to members of the PE working group. The Bulletin of Physical Education, 27, 29-33.

Armour, K., \& Harris, J. (2013). Making the case for developing new PE-for-health pedagogies. Quest, 65(2), 201-219.

Australian Curriculum, Assessment and Reporting Authority (ACARA). (2012). The Health and Physical Education Curriculum F-10. Sydney: ACARA.

Biddle, S.J.H., Ciaccioni, S, Thomas, G., \& Vergeer, I, (2019). Physical activity and mental health in children and adolescents: An updated review of reviews and an analysis of causality. Psychology of Sport \& Exercise, 42, 146-155.

Bowler, M. T. (2019). Developing a Pedagogical Model for Health-Based Physical Education. Doctoral Thesis, Loughborough University, UK.

Bowler, M., Sammon, P., Kirk, D., Haerens, L., Cale, L., \& Casey, A. (2015). Developing a 'prototype' Health-Based Physical Education pedagogical model. Paper presented at the International Association for Physical Education in Higher Education (AIESEP) Annual Conference, Universidad Europea, Madrid, Spain.

Burrows, L., \& Wright, J. (2004). The discursive production of childhood, identity and health. In J. Evans, B. Davies \& J. Wright (Eds). Body, Knowledge and Control, London: Routledge, pp. 83-96.

Burrows, L., Wright, J., \& McCormack, J. (2009). Dosing up on food and physical activity: New Zealand children's ideas about 'health'. Health Education Journal, 68(3), 157-169.

Cale, L. (1996). Health-related exercise in schools - PE has much to be proud of!, The British Journal of Physical Education, 27(4), 8-13.

Cale, L. (2017). Teaching about active lifestyles. In C.D. Ennis (Ed.), Routledge handbook of physical education pedagogies (pp. 399-411). Oxon, UK: Routledge.

Cale, L. (2019). Young people, social media, physical activity and health: Final thoughts on the work, the present, and the future. In V. Goodyear, and K.M. Armour (Eds.), Young people, social media and health (pp. 212-224). Oxon, UK: Routledge.

Cale, L., \& Harris, J. (2005). (Eds.), Exercise and young people. Issues, implications and initiatives. Basingstoke: Palgrave Macmillan. 
Cale, L., \& Harris, J. (2006). School based physical activity interventions - effectiveness, trends, issues, implications and recommendations for practice. Sport, Education and Society, 11(4), 401420.

Cale, L., \& Harris, J. (2009a). Getting the buggers fit. Second edition. London: Continuum.

Cale, L., \& Harris, J. (2009b). Fitness testing in physical education - a misdirected effort in promoting healthy lifestyles and physical activity? Physical Education and Sport Pedagogy, 14(1), 89-108.

Cale, L., \& Harris, J. (2013). Physical education and health: considerations and issues. In S. Capel \& M. Whitehead (Eds.), Debates in physical education (pp. 74-88). Oxon: Routledge.

Cale, L., \& Harris, J. (2018). The role of knowledge and understanding in fostering physical literacy. Journal of Teaching in Physical Education, 37(3), 280-287.

Cale, L., Harris, J., \& Chen, M.H. (2014). Monitoring health, activity and fitness in physical education: its current and future state of health. Sport Education and Society, 19(4), 376-397.

Cale, L., Harris, J., \& Duncombe, R. (2016). Promoting physical activity in secondary schools. Growing expectations: same old issues. European Physical Education Review, 22(4), 526-544.

Cale, L., Harris, J., \& Hooper, O. (2020). Debating health knowledge and pedagogies in physical education. In: S. Capel \& R. Blair (Eds.), Debates in physical education. Second edition. Routledge.

Cardon, G.M., Van Acker R., Seghers., J et al. (2012). Physical activity promotion in schools: which strategies do schools (not) implement and which socioecological factors are associated with implementation? Health Education Research 27(3): 470-483.

Casey, A., Goodyear, V.A., \& Armour, K. M. (2017). Rethinking the relationship between pedagogy, technology and learning in health and physical education. Sport, Education and Society, $22(2), 288-304$.

Department for Education and the Welsh Office. (1995). Physical Education in the National Curriculum. London: HMSO.

Department for Education. (2013). Programmes of study for physical education. Key stages 3 and 4 https://www.gov.uk/government/uploads/system/uploads/attachment _data/file/239086/SECONDARY_national_curriculum_-_Physical_education.pdf.

Dyson, B., Landi, D., \& Gordin, B. (2018). Redesign of PE in Aotearoa New Zealand. In H.A. Lawson (Ed.), Redesigning physical education. An equity agenda in which every child matters (pp. 182-195). Oxon: Routledge.

Enright, E., \& Gard, M. (2019). Young people, social media and digital democracy: Towards a participatory foundation for health and physical education's engagement with digital technologies. 
In V. Goodyear, \& K.M. Armour (Eds.), Young people, social media and health (pp. 177-191). Oxon: Routledge.

Evans, J. (2007). Health education or weight management in schools? Cardiometabolic Risk and Weight Management, 2(2), 12-16.

Evans, J., \& Rich, E. (2011). Body policies and body pedagogies: every child matters in totally pedagogised schools? Journal of Education Policy, 26(2),311-329.

Evans, J., Rich, E., Davies, B., \& Allwood, R. (2008). Education, Disordered Eating and Obesity Discourse. Fat Fabrications, Oxon: Routledge.

Fox, K. (1992). Education for exercise and the National Curriculum proposals: A step forward or backwards. The British Journal of Physical Education, 23(1), 8-11.

Fox, K., Cooper, A. \& McKenna, J. (2004). The school and promotion of children's healthenhancing physical activity: perspectives from the United Kingdom. Journal of Teaching Physical Education, 23, 338-358.

Gard, M. (2014). eHPE: A history of the future. Sport, Education and Society, 19(6), 827-845.

Green, K. (1994). Meeting the Challenge: Health Related Exercise and the encouragement of lifelong participation. The Bulletin of Physical Education, 30(3), 27-34.

Green, K. (2009). Exploring the everyday 'philosophies' of physical education teachers from a sociological perspective. In: R. Bailey \& D. Kirk (Eds.) The Routledge physical education reader (pp. 183-206). London: Routledge Taylor and Francis.

Green, K., Cale, L., \& Harris, J. (2018). Re-imagination and re-design in physical education. Implicit and explicit models in England and Wales. In H.A. Lawson. Redesigning physical education. An equity agenda in which every child matters (pp. 156-170). Oxon: Routledge.

Goodyear, V., Kerner, C., \& Quennerstedt, M. (2017). Young people's uses of wearable healthy lifestyle technologies; surveillance, self-surveillance and resistance. Sport, Education and Society, DOI: $10.1080 / 13573322.2017 .1375907$.

Haerens, L., Kirk, D., Cardon, G., \& De Bourdeaudhuij, I. (2011). Toward the development of a pedagogical model for health-based physical education. Quest, 63, 321-338.

Harris, J. (1993). Young people's perceptions of health, fitness and exercise. The British Journal of Physical Education Research Supplement, 13, 5-9.

Harris, J. (1994). Health related exercise in the national curriculum: results of a pilot study in secondary schools. The British Journal of Physical Education Research Supplement, 14, 6-11.

Harris, J. (1995). Physical education - a picture of health? The British Journal of Physical Education, 26(4), 25-32. 
Harris, J. (2000). Health-related exercise in the national curriculum. Leeds: Human Kinetics.

Harris, J. (2010). Health-related physical education. In R. Bailey (Ed.), Physical education for learning: A guide for secondary schools (pp, 26-36). London: Continuum.

Harris, J., \& Almond, L. (1991). Learning to care. The Bulletin of Physical Education, 27(1), 5-11.

Harris, J., \& Elbourn, J. (1992a). Highlighting health related exercise within the national curriculum-part 1. The British Journal of Physical Education, 23(1), 18-22.

Harris, J. \& Elbourn, J. (1992b). Highlighting health related exercise within the national curriculum-Part 2. The British Journal of Physical Education, 23(2), 5-9.

Harris, J., \& Leggett, G. (2015). Influences on the expression of health within physical education curricula in secondary schools in England and Wales. Sport Education and Society, 20(7), 908-923.

Harris, J., \& Cale, L. (2018). Promoting active lifestyles in schools. Leeds: Human Kinetics.

Harris, J. Cale, L., Casey, A., Tyne, A., \& Samaria, B. (2016). Promoting active lifestyles in schools. The PAL Project. Physical Education Matters, 11(3), 52-53.

Hastie, P. A., Chen, S., \& Guarino, A. J. (2017). Health-related fitness knowledge development through project-based learning. Journal of Teaching in Physical Education, 36, 119-125.

Health Education Authority. (1993). Health and physical education project newsletter, 32, 1-2.

Keating, X.D. (2003). The current often implemented fitness tests in physical education programs: problems and future directions. Quest, 55, 141-160.

Kirk, D. (2010). Four relational issues and the bigger picture. In: D. Kirk. Physical education futures (pp. 97-120). Abingdon Oxon: Routledge.

Kirk, D. (2019). School physical education and learning about health: Pedagogical strategies for using social media. In V. Goodyear, \& K.M. Armour (Eds.), Young people, social media and health (pp. 86-100). London: Routledge.

Kirk, D., Bardid, F., Lamb, C.A., Millar, J.D., \& Teraoka, E. (2018). Redesigning physical education in Scotland. In H.A. Lawson. Redesigning physical education. An equity agenda in which every child matters (pp. 145-155). Oxon: Routledge,

Laarson, H., \& Quennerstedt, M. (2016). Same, same but different: Re(understanding the place of context in physical education practice. Researches \& Educations, 15, 65-83.

Larsen, T., Tjomsland, H., \& Samdal, O. (2013). Physical activity in schools. A qualitative case study of eight Norwegian schools' experiences with the implementation of a national policy. Health Education, 113(1), 52-63.

Lawson, H.A. (Ed.). (2018). Redesigning physical education. An equity agenda in which every child matters. Oxon: Routledge. 
Leahy, D., Burrows, L., McCuaig, L., Wright, J., \& Penney, D. (2016). School Health Education in Changing Times. London: Routledge.

Lloyd, M., Colley, R., \& Tremblay, M.S. (2010). Advancing the debate on fitness testing for children: Perhaps we're riding the wrong animal. Pediatric Exercise Science, 22, 176-182.

Lupton, D. (2016). The diverse domains of quantified selves: Self-tracking modes and dataveillance. Economy and Society, 45(1), 101-122.

Macdonald, D., Enright, E., \& McCuaig, L. (2018). Re-visioning the Australian curriculum for health and physical education. In H.A. Lawson. Redesigning physical education. An equity agenda in which every child matters (pp. 196-209). Oxon: Routledge,

Marks, R. (2008). Schools and health education. What works, what is needed, and why? Health Education 109(1), 4-8.

McKenzie, T.L., \& Lounsbery, M.A.F. (2009). School physical education: the pill not taken. American Journal of Lifestyle Medicine, 3(3), 219-225.

Metzler, M., McKenzie, T., Van der Mars, H., Barrett-Williams, S. \& Ellis, R. (2013). Health Optimizing Physical Education (HOPE): A new curriculum for school programs - Part 1: establishing the need and describing the model. Journal of Physical Education, Recreation and Dance, 84(4), 41-47.

Ministry of Education (2007). The New Zealand curriculum. Wellington, New Zealand: Learning Media.

National Curriculum Council. (1990). Curriculum guidance 5: Health education. London: HMSO.

Naughton, G.A., Carlson, J.S., \& Greene, D.A. (2006). A challenge to fitness testing in primary schools. Journal of Science and Medicine in Sport, 9, 40-45.

Office for Standards in Education. (2005). Physical education in secondary schools. London: Author.

Oliver, K.M., \& Kirk, D. (2016). Towards an activist approach to research and advocacy for girls and physical education. Physical Education and Sport Pedagogy, 21, 313-327.

O'Sullivan, M. (2004). Possibilities and pitfalls of a public health agenda for physical education, Journal of Teaching in Physical Education, 23, 392-404.

Oxley, J. (1994). HRE and the national curriculum - an OFSTED inspector's view. The Bulletin of Physical Education, 30(2), 39.

Puhse, U., Barker, D., Brettschneider, W.D., Feldmeth, A.K. et al., (2011). International approaches to health-oriented physical education: local health debates and differing conceptions of health.

International Journal of Physical Education, 3, 2-15. 
Quennerstedt, M. (2008). Exploring the relation between physical activity and health - a salutogenic approach to physical education. Sport, Education and Society, 13(3), 276-283.

Quennerstedt, M. (2019). Healthying physical education - on the possibility of learning health. Physical Education and Sport Pedagogy, 24(1), 1-15.

Rich, E., \& Miah, A. (2017). Mobile, wearable and ingestible health technologies: Towards a critical research agenda. Health Sociology Review, 26(1), 84-97.

Silverman, S., Keating, X.D., \& Phillips, S.R. (2008). A lasting impression: a pedagogical perspective on youth fitness testing. Measurement in Physical Education, 12, 146-166.

Sleap, M. (1990). Promoting health in primary school physical education. In N. Armstrong (Ed.), New Directions in physical education (pp 17-36). Champaign, IL: Human Kinetics.

Sykes, H., \& McPhail, D (2008). Unbearable lessons: Contesting fat phobia in physical education. Sociology of Sport Journal, 25(1), 66-96.

Thorburn, M. (Ed.). (2018). Wellbeing, education and contemporary schooling. London: Routledge.

Thorburn, M., \& Gray, S. (2010). Physical education: Picking up the baton. Edinburgh: Dunedin.

Tinning, R. (2010). Pedagogy and human movement: Theory, practice, research. Oxon: Routledge.

Trost, S. (2006). Public health and physical education. In: D. Kirk, M. O'Sullivan \& D. Macdonald (Eds.), Handbook of physical education (pp. 163-187). London, Sage.

Wellard, I. (2012). Body-reflexive pleasures: exploring bodily experiences within the context of sport and physical activity. Sport, Education and Society, 17(1), 21-33.

Williamson, B. (2015). Algorithmic skin: Health-tracking technologies, personal analytics and the biopedagogies of digitized health and physical education. Sport, Education and Society, 20(1), 133151.

Wrench, A., \& Garrett, R. (2008). Pleasure and pain: experiences of fitness testing. European Physical Education Review, 14(3), 325-346.

World Health Organisation (2018). Adolescent Mental Health Factsheet https://www.who.int/newsroom/fact-sheets/detail/adolescent-mental-health 